\title{
Distinct Mechanisms Underlie Neurotoxin-Mediated Cell Death in Cultured Dopaminergic Neurons
}

\author{
Julie Lotharius, ${ }^{1}$ Laura L. Dugan, ${ }^{2}$ and Karen L. O'Malley ${ }^{1}$ \\ ${ }^{1}$ Department of Anatomy and Neurobiology and ${ }^{2}$ Center for the Study of Nervous System Injury, Washington University \\ School of Medicine, St. Louis, Missouri 63110
}

\begin{abstract}
Oxidative stress is thought to contribute to dopaminergic cell death in Parkinson's disease (PD). The neurotoxin 6-hydroxydopamine (6-OHDA), which is easily oxidized to reactive oxygen species (ROS), appears to induce neuronal death by a free radical-mediated mechanism, whereas the involvement of free radicals in $\mathrm{N}$-methyl-4-phenylpyridinium $\left(\mathrm{MPP}^{+}\right)$toxicity is less clear. Using free radical-sensitive fluorophores and vital dyes with post hoc identification of tyrosine hydroxylase-positive neurons, we monitored markers of apoptosis and the production of ROS in dopaminergic neurons treated with either 6-OHDA or MPP ${ }^{+}$. Annexin-V staining suggested that 6-OHDA but not $\mathrm{MPP}^{+}$-mediated cell death was apoptotic. In accordance with this assignment, the general caspase inhibitor Boc(Asp)-fluoromethylketone only blocked 6-OHDA neurotoxicity. Both toxins exhibited an early, sustained rise in ROS, although only 6-OHDA induced a collapse in mitochondrial membrane
\end{abstract}

potential temporally related to the increase in ROS. Recently, derivatives of buckminsterfullerene $\left(\mathrm{C}_{60}\right)$ molecules have been shown to act as potent antioxidants in several models of oxidative stress (Dugan et al., 1997). Significant, dose-dependent levels of protection were also seen in these in vitro models of $\mathrm{PD}$ using the $\mathrm{C}_{3}$ carboxyfullerene derivative. Specifically, $\mathrm{C}_{3}$ was fully protective in the 6-OHDA paradigm, whereas it only partially rescued dopaminergic neurons from $\mathrm{MPP}^{+}$-induced cell death. In either model, it was more effective than glialderived neurotrophic factor. These data suggest that cell death in response to $6-\mathrm{OHDA}$ and $\mathrm{MPP}^{+}$may progress through different mechanisms, which can be partially or entirely saved by carboxyfullerenes.

Key words: dihydrorhodamine; dihydroethidium; rhodamine 123; neuroprotection; MPTP; mesencephalic
Parkinson's disease (PD) is a progressive disorder characterized by the loss of nigrostriatal neurons. The resulting striatal deficiency leads to the parkinsonian syndrome of bradykinesia, rigidity, and motor and postural instability. Although the etiology of PD remains unknown, an accumulating body of evidence suggests that impaired energy metabolism and factors leading to increased oxidative stress may be involved. For example, mitochondrial dysfunction, lipid peroxidation, increased accumulation of free iron, and increased superoxide dismutase activity have all been implicated in nigral cell death (for review, see Jenner, 1998).

The selective neurotoxins 1-methyl-1,2,3,6-tetrahydropyridine (MPTP) and 6-hydroxydopamine (6-OHDA) have been widely used to generate animal models of PD. When administered in vivo, both toxins cause a parkinsonian condition marked by decreased dopamine levels and tyrosine hydroxylase (TH) activity, impaired dopamine uptake, and an ensuing loss of dopaminergic neurons. Given the parallels with PD, the mechanism by which these compounds lead to dopaminergic cell death is of great interest. Earlier studies have shown that 6-OHDA is transported into dopaminergic neurons where it is oxidized to produce hydrogen peroxide, superoxide, and hydroxyl radicals (Cohen and Heikkila, 1974; Graham et al., 1978). 6-OHDA has also been

\footnotetext{
Received Sept. 28, 1998; revised Nov. 9, 1998; accepted Nov. 25, 1998.

This work was supported by the National Parkinson's Foundation (K.L.O), and by National Institutes of Health Grants MH45330 (K.L.O.), AG00599 (L.L.D.), and NS37688 (L.L.D.). J.L. was supported in part by the Systems and Molecular Neurobiology Training Grant 5-T32-GM08151 (National Institutes of Health). We thank Dr. G. Kapatos for generously providing the mouse TH antibody; Dr. D. Choi for use of the Noran confocal microscope; Dr. J. Lichtman for the use of the Fluoview confocal microscope; and M. Moffat for assistance with cell culture techniques. Copyright (C) 1999 Society for Neuroscience $\quad 0270-6474 / 99 / 191284-10 \$ 05.00 / 0$
}

shown to inhibit mitochondrial Complex I and IV in vitro (Glinka and Youdim, 1995). In contrast, the mechanism(s) by which MPTP or its toxic metabolite 1-methyl-4-phenylpyridinium $\left(\mathrm{MPP}^{+}\right)$kills cells is less clear.

Numerous studies have suggested that $\mathrm{MPP}^{+}$blocks NADHdehydrogenase-linked oxidation, leading to a loss in ATP and secondarily the formation of superoxide (for review, see Przedborski and Jackson-Lewis, 1998). These data are supported by the observation that transgenic mice overexpressing superoxide dismutase are resistant to MPTP toxicity (Przedborski et al., 1992). Superoxide can interact with nitric oxide to form the highly reactive peroxynitrite radical, or it can react with iron or copper to generate hydroxyl radicals. Evidence for the former pathway comes from studies showing that inhibition of nitric oxide synthase can protect mice (Smith et al., 1994; Przedborski et al., 1996) and baboons (Hantraye et al., 1996) from MPTP neurotoxicity. In contrast, other studies have suggested that mitochondrial impairment is not a primary factor in toxin-mediated cell death in vivo, because Complex I activity undergoes only a small, transient reduction in response to MPTP (Gerlach et al., 1996), and $\mathrm{MPP}^{+}$kills Rho 0 cells that lack functional mitochondria at doses equivalent to those that kill normal cells (Khan et al., 1997). Thus, reactive oxygen species (ROS) production attributable to impaired Complex I activity may not be the instigator of MPTPinduced cell death but rather a byproduct of this process.

To more clearly define the involvement of free radicals in 6-OHDA and $\mathrm{MPP}^{+}$neurotoxicity, we monitored ROS levels, mitochondrial membrane potential, and several markers of apoptosis in identified primary dopaminergic neurons. Together with the dopaminergic neuroprotectant glial cell line-derived neuro- 
trophic factor (GDNF), novel, potent free radical scavengers, the carboxyfullerenes, were assessed for their ability to attenuate 6-OHDA- and $\mathrm{MPP}^{+}$-mediated toxicity. Although both toxins induced oxidative stress, in contrast to $\mathrm{MPP}^{+}$, neurons treated with 6-OHDA died via apoptosis and were completely protected by carboxyfullerenes. Thus, $\mathrm{MPP}^{+}$and 6-OHDA induce distinct mechanisms of cell death in dopaminergic neurons.

\section{MATERIALS AND METHODS}

\section{Mesencephalic cultures}

The ventral mesencephalon was removed from embryonic day 14 (E14) CF1 murine embryos (Charles River Laboratories, Wilmington, MA). Tissues were mechanically dissociated, incubated with $0.25 \%$ trypsin and $0.05 \%$ DNase in PBS for $30 \mathrm{~min}$ at $37^{\circ} \mathrm{C}$, and further triturated using a constricted Pasteur pipette. For immunocytochemistry, cells were plated at a density of 100,000 cells per $35 \mathrm{~mm}$ microwell plate $\left(1.25 \times 10^{3}\right.$ cells $/ \mathrm{mm}^{2}$ ). All plates were precoated overnight with $0.5 \mathrm{mg} / \mathrm{ml}$ poly-Dlysine followed by $2.5 \mu \mathrm{g} / \mathrm{ml}$ laminin for $2 \mathrm{hr}$ at room temperature. Initial plating was performed in serum-containing medium consisting of $10 \%$ fetal calf serum in DMEM/F1 supplemented with B27 additive (Life Technologies, Gaithersburg, MD), $6 \mathrm{gm} / 1$ glucose, and antibacterial agents. Near-pure neuronal cultures $(<0.5 \%$ glia determined by glial fibrillary acidic protein staining) were achieved by subsequently maintaining cells in serum-free Neurobasal medium (Life Technologies) supplemented with $0.5 \mathrm{~mm}$ L-glutamine, $0.01 \mu \mathrm{g} / \mathrm{ml}$ streptomycin $/ 100 \mathrm{U}$ penicillin, and $1 \times \mathrm{B} 27$ supplement. Half of the culture medium was replaced with fresh Neurobasal medium every $48 \mathrm{hr}$. Experiments were performed after $7 \mathrm{~d}$ in vitro (DIV7) unless specified otherwise.

\section{Chemicals}

$\mathrm{MPP}^{+}$iodide, 1-aminoindan-1,5-dicarboxylic acid (AIDA), 1,2,3,4tetrahydro-6-nitro-2,3-dioxo-benzo(f)quinoxaline-7-sulfonamide (NBQX), (5S,10R)-(-)-5-methyl-10,11-dihydro-5H-dibenzo[a,d]cyclohepten-5,10imine hydrogen malate (MK-801), and nifedipine were all purchased from Research Biochemicals (Natick, MA). 6-OHDA, D(+)-glucose, and succinate were purchased from Sigma (St. Louis, MO). The $\mathrm{C}_{3}$ isomer of malonic acid, $\mathrm{C}_{60}$, was prepared as described previously (Dugan et al., 1997). Boc-(Asp)-fluoromethylketone (BAF) was obtained from Enzyme Systems Products (Livermore, CA), and human recombinant GDNF (hrGDNF) was from Promega (Madison, WI). 7-Nitroindazole (7-NI) and $\mathrm{N}^{\mathrm{G}}$-nitro-L-arginine (L-NNA) were both obtained from CalbiochemNovabiochem (La Jolla, CA).

\section{Treatment with neuroprotective agents}

Glutamate receptor/calcium channel blockers. 1-10 $\mu \mathrm{M}$ MK-801, 30-100 $\mu \mathrm{M}$ NBQX, 100-300 $\mu \mathrm{M}$ AIDA, and 1-10 $\mu \mathrm{M}$ nifedipine were added 30 min before $\mathrm{MPP}^{+}$exposure.

Nitric oxide synthase inhibitors. Neurons were pretreated with $0.5-2.5$ mM L-NNA or 5-20 $\mu \mathrm{M}$ 7-NI for $3 \mathrm{hr}$ before application of $\mathrm{MPP}^{+}$

Metabolic substrates. $0.5-5 \mathrm{~mm}$ succinate and $10-30 \mathrm{~mm}$ glucose (applied once or every $6 \mathrm{hr}$ ) were added simultaneously with $\mathrm{MPP}^{+}$. All chemicals, with the exception of 7-NI and NBQX (which were dissolved in DMSO), were dissolved in water. For 7-NI and NBQX, the final DMSO concentration did not exceed $0.2 \%$. Cultures were treated with hrGDNF (dissolved in water containing $1 \mathrm{mg} / \mathrm{ml} \mathrm{BSA}$ and stored at $-80^{\circ} \mathrm{C}$ until use) for 3 or $6 \mathrm{hr}$ before $\mathrm{MPP}^{+}$exposure. The $\mathrm{C}_{3}$ fullerene isomer was prepared fresh in a $25 \mathrm{~mm}$ stock dissolved in water and used at concentrations ranging from 1 to $100 \mu \mathrm{M}$.

\section{Determination of cell viability}

To determine the effect of 6-OHDA and $\mathrm{MPP}^{+}$on dopaminergic cell viability, mesencephalic cultures were processed for $\mathrm{TH}$ immunoreactivity. Briefly, cells were rinsed with PBS, fixed in $4 \%$ paraformaldehyde, permeabilized in $1 \%$ bovine serum albumin/0.1\% Triton X-100/PBS for $30 \mathrm{~min}$ at room temperature, and incubated with a mouse monoclonal anti-TH antibody (1:1000; kindly provided by Dr. Greg Kapatos, Wayne State University) for $1 \mathrm{hr}$ at $37^{\circ} \mathrm{C}$. Cells were subsequently incubated with a biotinylated goat anti-mouse IgG (1:100; Jackson Immunoresearch, West Grove, PA) for $40 \mathrm{~min}$ at room temperature and visualized via an alkaline phosphatase-driven color reaction. For some experiments, cells were incubated with a CY3-conjugated anti-mouse $\mathrm{IgG}$ (1:250; Jackson Immunoresearch). The number of surviving TH-positive neurons was counted and normalized to the number of $\mathrm{TH}$ cells in untreated cultures. Nuclear morphology was assessed by incubating cells with $10 \mu \mathrm{g} / \mathrm{ml}$ Hoechst 33258 (Molecular Probes, Eugene, OR) for $3 \mathrm{~min}$ at room temperature followed by fluorescence microscopy using a UVexcitation filter. Loss of membrane asymmetry attributable to phosphatidyl translocation was assessed using a human recombinant annexin-VFITC conjugate (Research and Diagnostics, Minneapolis, MN) using a modification of the manufacturer's instructions developed by L. Dugan. To do so, cells were washed twice with PBS and incubated with $10 \mu \mathrm{g} / \mathrm{ml}$ annexin-V-FITC in binding buffer consisting of $25 \mathrm{mM} \mathrm{CaCl}_{2}, 10 \mathrm{~mm}$ HEPES-NaOH, and $140 \mathrm{~mm} \mathrm{NaCl}$ for $10 \mathrm{~min}$ at room temperature. Cells remained in excess binding buffer until imaging. Loss of viability was also measured by incubating cells with $0.04 \%$ Trypan blue (Sigma). Manual cell counts were conducted by a person blinded to the experimental condition by scoring photomicrographs taken from six consecutive fields $(20 \times$ objective) across a culture well. This typically yields approximately $300 \mathrm{TH}$-positive cells in control cultures. Time points of 24 and $48 \mathrm{hr}$ were chosen because cells responding to 6-OHDA or $\mathrm{MPP}^{+}$, respectively, were completely gone. Thus, assessment of remaining cells was not based on alterations in soma size.

\section{Imaging}

Dopaminergic neurons were identified in situ using the autofluorescent serotonin analog 5-7,dihydroxytryptamine (5,7-DHT; Sigma) (Silva et al., 1988). Briefly, DIV7 mesencephalic cultures were treated with $1 \mu \mathrm{M}$ $\mathrm{MPP}^{+}$for $0.5,1,3,6,12$, and $24 \mathrm{hr}$ and co-incubated with $10 \mu \mathrm{M}$ 5,7-DHT (dissolved in 1\% ascorbic acid) and $15 \mu \mathrm{M}$ dihydrorhodamine 123 (DHR) (Molecular Probes; dissolved in DMSO) for $30 \mathrm{~min}$ at $37^{\circ} \mathrm{C}$. Cultures were washed twice with DMEM $/ 0.1 \mathrm{mg} / \mathrm{ml}$ ascorbic acid $/ 12 \mathrm{~mm}$ HEPES to remove excess reagents, and dopaminergic cells were first identified at $60 \times$ using a near-UV excitation filter (Omega Optical; excitation $(\mathrm{Ex})=330 \mathrm{~nm}$, emission $(\mathrm{Em})=450 \mathrm{~nm}$ ) and then imaged with a laser-scanning confocal microscope (Noran Instruments) using a $488 \mathrm{~nm}$ excitation filter $(\mathrm{Em}>515)$. The measured, cytoplasmic DHR fluorescence (pixel intensity) of 5,7-DHT-positive cells was obtained using a computerized image analysis program (Metamorph, Universal Imaging), averaged, and normalized to control values. A total of 50-75 cells was assayed per condition in three separate experiments. Alternately, dihydroethidium (DHE) (Molecular Probes) was used to detect superoxide formation in toxin-treated cultures. Individual cultures were treated with $15 \mu \mathrm{M} 6-\mathrm{OHDA}$ or $1 \mu \mathrm{M} \mathrm{MPP}^{+}$for $0,0.25,0.5,1,3$, and 6 $\mathrm{hr}$, incubated with $10 \mu \mathrm{g} / \mathrm{ml} \mathrm{DHE} \mathrm{(dissolved} \mathrm{in} \mathrm{DMSO)} \mathrm{for} 15 \mathrm{~min}$ at $37^{\circ} \mathrm{C}$, and fixed with $4 \%$ paraformaldehyde for $30 \mathrm{~min}$ at room temperature. Cultures were then processed for $\mathrm{TH}$ immunoreactivity using an alkaline phosphatase-mediated color reaction, and fields containing THpositive neurons were imaged by confocal microscopy $(\mathrm{Ex}=488 \mathrm{~nm}$; $\mathrm{Em}=595 \mathrm{~nm}$ ). The total ethidium fluorescence from post hoc-identified dopaminergic neurons was measured using an image analysis system and normalized to DHE fluorescence from vehicle-treated TH-positive neurons. A minimum of 30 cells were assayed per condition in three separate experiments. To measure changes in mitochondrial membrane potential, neurotoxin-treated cells were loaded with $0.3 \mu \mathrm{M}$ rhodamine $123(\mathrm{Rh}$ 123) (Molecular Probes; dissolved in DMSO) after 0, 1, 6, 12, and $24 \mathrm{hr}$ and assayed in the same manner as DHR imaging. In experiments involving $\mathrm{C}_{3}$ and $\mathrm{BAF}$, neurons were imaged with a Fluoview confocal microscope (Olympus America).

\section{Statistics}

Descriptive statistics (mean \pm SEM) of cell survival counts were calculated with statistical software (GraphPad Prism Software). Cell survival curves were generated using the mean \pm SEM with data collected from three separate cultures. The significance of effects between control cultures and drug or neuroprotectant treatments was determined by one-way ANOVA and post hoc Student's $t$ tests (GraphPad Prism Software). If significant differences were observed, then post hoc pairwise comparisons were performed for individual drug concentrations.

\section{RESULTS}

Dopaminergic neurons treated with 6-OHDA display morphological and biochemical features of apoptosis, whereas MPP ${ }^{+}$-treated neurons do not

To determine whether 6-OHDA and $\mathrm{MPP}^{+}$induce apoptosis in primary dopaminergic neurons, we monitored the appearance of 
phosphatidylserine in the outer plasma membrane leaflet, an early apoptotic marker (for review, see van Engeland et al., 1998), followed by post hoc identification of $\mathrm{TH}$-immunoreactive neurons. Typically, the latter constituted $1-5 \%$ of the total cells plated. Using toxin concentrations that induced $50-70 \%$ cell death in identified dopaminergic neurons (Fig. $1 A$ ), mesencephalic cultures were treated with either 6-OHDA or $\mathrm{MPP}^{+}$for 6 hr before exposure with an annexin-V-FITC conjugate. Because neuronal degeneration begins at $>12 \mathrm{hr}$, this time point was chosen because $\mathrm{TH}$ immunoreactivity can still be detected. After treatment with 6-OHDA, intense annexin-V staining was visualized that uniformly surrounded cell somas and was present in some processes as well (Fig. $1 B$, left panel). Under higher magnification the staining pattern appeared punctate (data not shown), in keeping with reports that individual PS residues are externalized during apoptosis. At this time point, as well as at 3 hr (data not shown), 83\% of dopaminergic neurons identified by TH immunoreactivity were annexin-V positive $(n=28)$. Overall, $30-50 \%$ of the neurons in the dish were annexin- $\mathrm{V}$ positive, a much greater increase than expected given the small percentage of dopaminergic neurons in the culture, suggesting that 6-OHDA also affects nondopaminergic neurons. Similar results were seen with other assays of cell death. For example, incubation with the DNA intercalating dye, Hoechst 33258, revealed a $212 \%$ increase in condensed, lobulated nuclei, another apoptotic hallmark. Similarly, a 335\% increase in the number of dead cells per 6-OHDAtreated culture was observed using Trypan blue exclusion. Similar to controls (Fig. 1B, top panel), very few annexin-V cells were observed in response to $\mathrm{MPP}^{+}$treatment $(1.6 \%)$ (Fig. $1 B$, bottom panel), none of which exhibited TH immunoreactivity $(n=31)$. Similar results were observed at 3, 12, and $24 \mathrm{hr}$ (data not shown).

Activation of cysteinyl aspartate-specific proteases (caspases) is a key event in apoptosis (for review, see Thornberry and Lazebnik, 1998). To assess whether the general caspase inhibitor BAF could block either 6-OHDA- or $\mathrm{MPP}^{+}$-mediated cell death, cultures were treated with varying concentrations of this protectant. Application of $50 \mu \mathrm{M}$ BAF maximally protected dopaminergic neurons from 6-OHDA-induced toxicity (78.7\% recovery), whereas BAF failed to protect $\mathrm{TH}$-positive neurons from $\mathrm{MPP}^{+}$ toxicity at concentrations ranging from 1 to $100 \mu \mathrm{M}$ (Fig. $2 A, B$ ). Higher doses of BAF ( $\geq 100 \mu \mathrm{M})$ were cytotoxic. Thus, by these morphological and pharmacological measures, 6-OHDA induces apoptosis in dopaminergic and nondopaminergic neurons, whereas $\mathrm{MPP}^{+}$does not.

\section{Distinct mitochondrial responses to 6-OHDA and MPP ${ }^{+}$}

To determine whether changes in mitochondrial function were associated with 6-OHDA and $\mathrm{MPP}^{+}$-mediated cell death, we used confocal microscopy together with several fluorophores to measure mitochondrial membrane potential $\left(\Delta \Psi_{\mathrm{m}}\right)$ and free radical production. Specific changes in dopaminergic neurons were examined by either preloading cultures with 5,7-DHT or post hoc identifying cells using TH immunocytochemistry and field relocation (Fig. 3). The drug 5,7-DHT is an autofluorescent serotonin analog that has been shown to identify living dopaminergic neurons (Silva et al., 1988; Cardozo, 1993; de Erausquin et al., 1994; Cardozo and Bean, 1995). Low doses of this drug $(10 \mu \mathrm{M})$ for short time periods ( $\leq 30 \mathrm{~min}$ ) did not appear to affect the ROS state of the cell or its viability $24 \mathrm{hr}$ later (data not shown). Using the fluorescent, cationic dye Rh 123 , which preferentially intercalates into the inside-negative inner mitochondrial membrane, distinct responses between these toxins were observed in mitochondrial membrane potential, particularly at early time points (Fig. $4 A$ ). Neurotoxic doses of 6-OHDA $(15 \mu \mathrm{M})$ resulted in rapid mitochondrial depolarization that recovered and even hyperpolarized at later time points. In contrast, dopaminergic neurons treated with $\mathrm{MPP}^{+}(1 \mu \mathrm{M})$ did not undergo significant mitochondrial depolarization until $12 \mathrm{hr}$ after treatment (Fig. 4A). The latter observation allowed us to use oxidation of DHR to Rh 123 by hydroxyl radicals (Royall and Ischoropoulos, 1993; Dugan et al., 1995) as a measure of ROS production in $\mathrm{MPP}^{+}$-treated 5,7-DHT-positive neurons. $\mathrm{MPP}^{+}$induced an early, timedependent burst of free radical species (Fig. 4B).

Because DHR oxidation relies on an intact mitochondrial membrane potential, which is dissipated by 6-OHDA, this compound could not be used to measure ROS generation in the 6-OHDA model. Instead we used DHE, which reacts with superoxide to generate ethidium (Bindokas et al., 1996). Given the stability of ethidium intercalation into DNA, imaged cultures could be evaluated by post hoc $\mathrm{TH}$ staining and field relocation. Confocal analysis of 6-OHDA showed a twofold increase in the level of DHE fluorescence in identified dopaminergic neurons beginning within minutes of drug exposure (Fig. 4C). Increased production peaked at $1 \mathrm{hr}$ and was less substantial at later time points. $\mathrm{MPP}^{+}$induced a slightly slower, threefold increase in DHE fluorescence that peaked at 2-3 hr. Thus, both toxins generate ROS in dopaminergic neurons.

\section{Carboxyfullerenes differentially rescue dopaminergic neurons from neurotoxin treatment}

Carboxyfullerenes have been shown to act as potent free radical scavengers in several models of oxidative stress in vivo and in vitro (Dugan et al., 1997). Because both 6-OHDA and MPP ${ }^{+}$induce free radical production in dopaminergic neurons (Fig. 4), we sought to determine whether the carboxyfullerene derivative $\mathrm{C}_{3}$ could block the toxic effects of these drugs. In keeping with the extent of the oxidative injury, the $\mathrm{C}_{3}$ isomer dramatically rescued dopaminergic neurons from 6-OHDA-induced cell death in a dose-dependent manner (92\% recovery at the highest dose), whereas it quickly plateaued in the case of $\mathrm{MPP}^{+}(37.5 \%$ recovery) (Fig. $5 A, B)$. Concentrations of $\mathrm{C}_{3}$ higher than $100 \mu \mathrm{M}$ were cytotoxic.

\section{The fullerene isomer $C_{3}$ is more effective than GDNF in protecting neurons from 6-OHDA and MPP ${ }^{+}$ neurotoxicity}

Trophic factors including GDNF have been shown to support the growth and survival of dopaminergic neurons both in vivo and in vitro (Lapchak, 1998). Therefore, we compared the ability of GDNF to protect cultured dopaminergic neurons from 6-OHDAand $\mathrm{MPP}^{+}$-induced toxicity with that of the fullerene derivative $\mathrm{C}_{3}$. Cells were treated with human recombinant GDNF and/or the $\mathrm{C}_{3}$ isomer together with 6-OHDA or $\mathrm{MPP}^{+}$. GDNF attenuated $38 \%$ of the 6-OHDA neurotoxic injury versus $92 \%$ for $\mathrm{C}_{3}$ (Fig. 6). GDNF promoted a $29 \%$ recovery in the $\mathrm{MPP}^{+}$paradigm, whereas $\mathrm{C}_{3}$ by itself promoted a $37.5 \%$ recovery of $\mathrm{MPP}^{+}$mediated cell death. Thus, $\mathrm{C}_{3}$ is more effective than GDNF in rescuing dopaminergic neurons from 6-OHDA- or $\mathrm{MPP}^{+}$mediated cell death.

\section{Other neuroprotectants do not block MPP ${ }^{+}$toxicity}

Besides oxidative stress, other possible mechanisms that could contribute to $\mathrm{MPP}^{+}$-induced cell death include loss of energy metabolism, secondary excitotoxicity, and elevated intracellular 

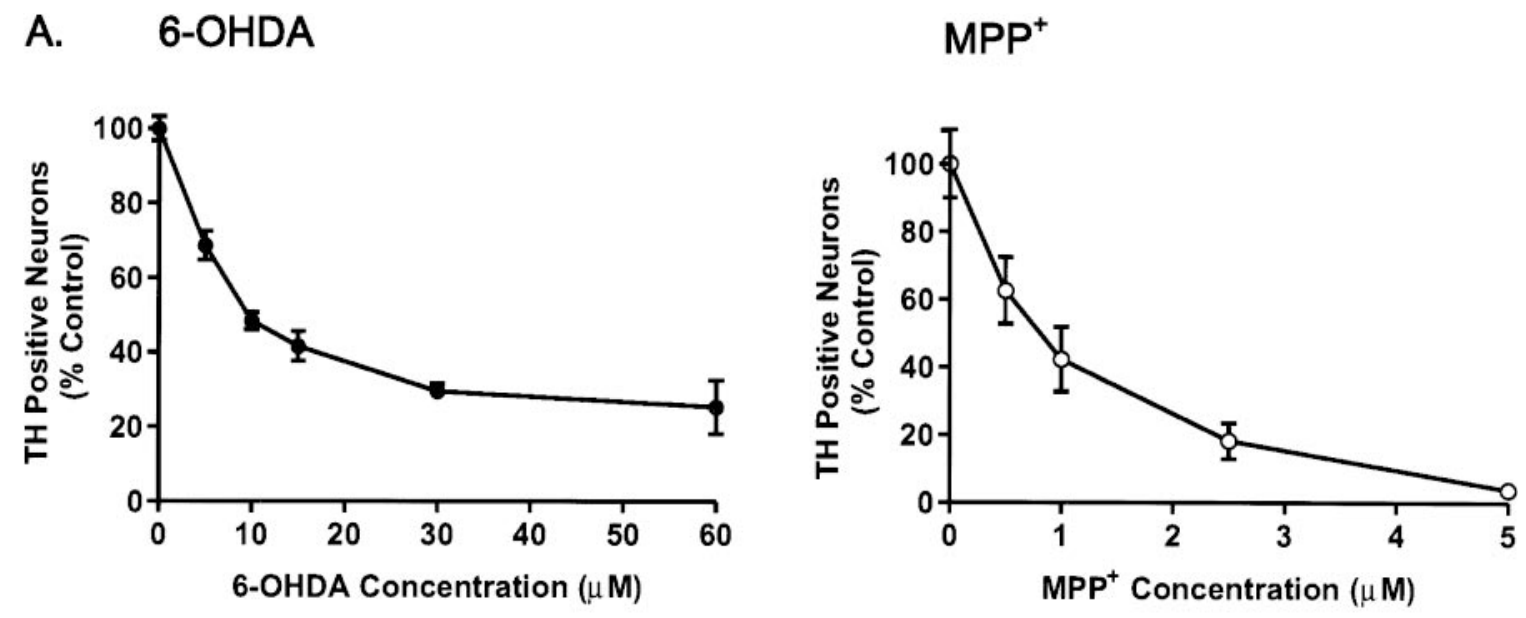

B.

Annexin-V-FITC
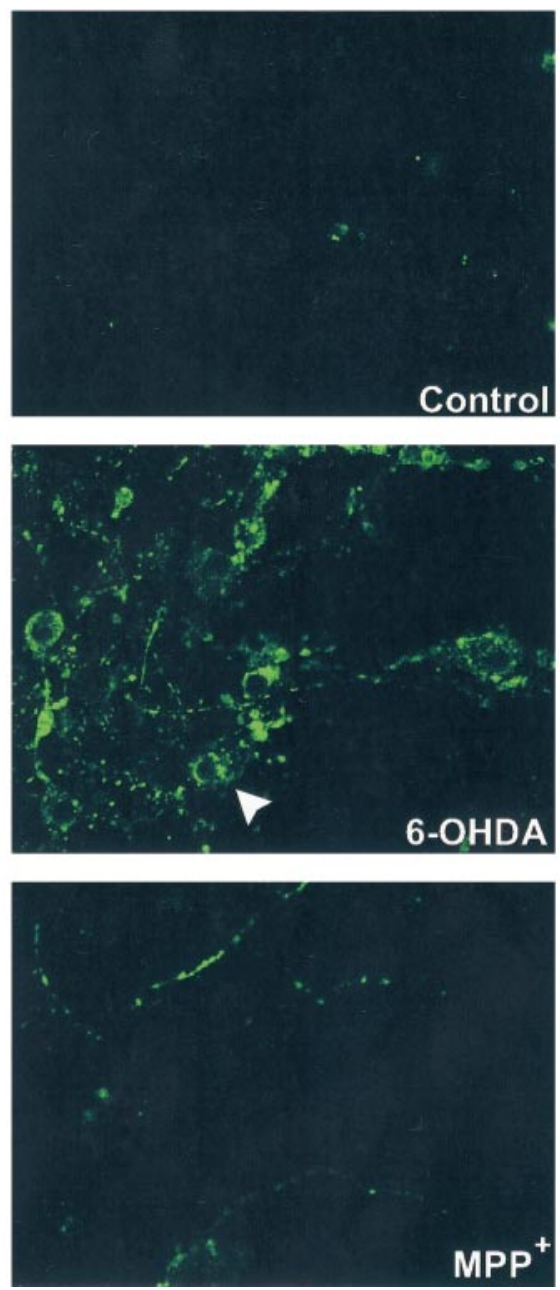

Tyrosine Hydroxylase
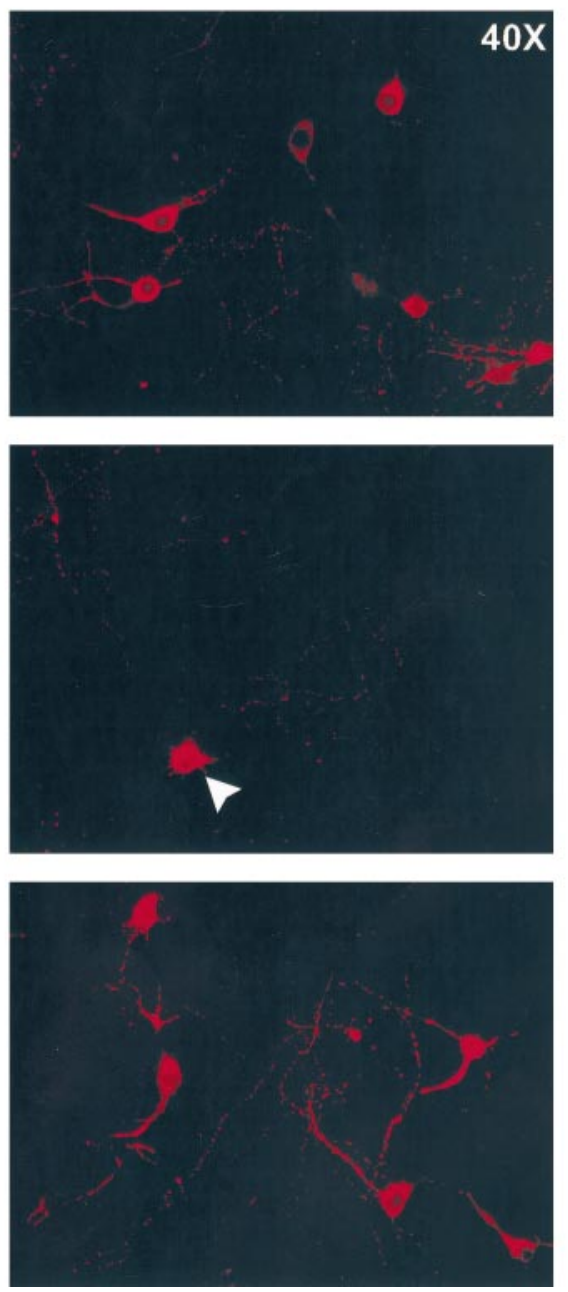

Figure 1. Plasma membrane alterations induced by 6-OHDA and $\mathrm{MPP}^{+} . A$, Cultures were treated with various concentrations of 6-OHDA or MPP ${ }^{+}$ for 24 and $48 \mathrm{hr}$, respectively, and processed for TH immunoreactivity, and the number of TH-positive neurons was counted. Data are normalized to control cultures and denote the mean \pm SEM of representative determinations made in three separate cultures. Bars with $<2 \%$ SEM are buried within the symbols. Cells exposed to 6-OHDA or $\mathrm{MPP}^{+}$exhibited a half-lethal dose of $15 \mu \mathrm{M}$ and $1 \mu \mathrm{M}$, respectively. $B$, Representative confocal micrographs of mesencephalic cultures stained for TH and annexin-V-FITC visualized at $40 \times$ magnification by confocal microscopy. Cultures were treated with 15 $\mu \mathrm{M}$ 6-OHDA or $1 \mu \mathrm{M} \mathrm{MPP}{ }^{+}$for $6 \mathrm{hr}$, rinsed, and incubated with annexin-V-FITC for $10 \mathrm{~min}$ at room temperature. After imaging, plates were fixed and processed for TH immunoreactivity using a CY3-coupled secondary antibody. Random micrographic fields of annexin-V-stained neurons were relocated by their position on a microwell grid, and the corresponding image of TH immunoreactive neurons was taken. 

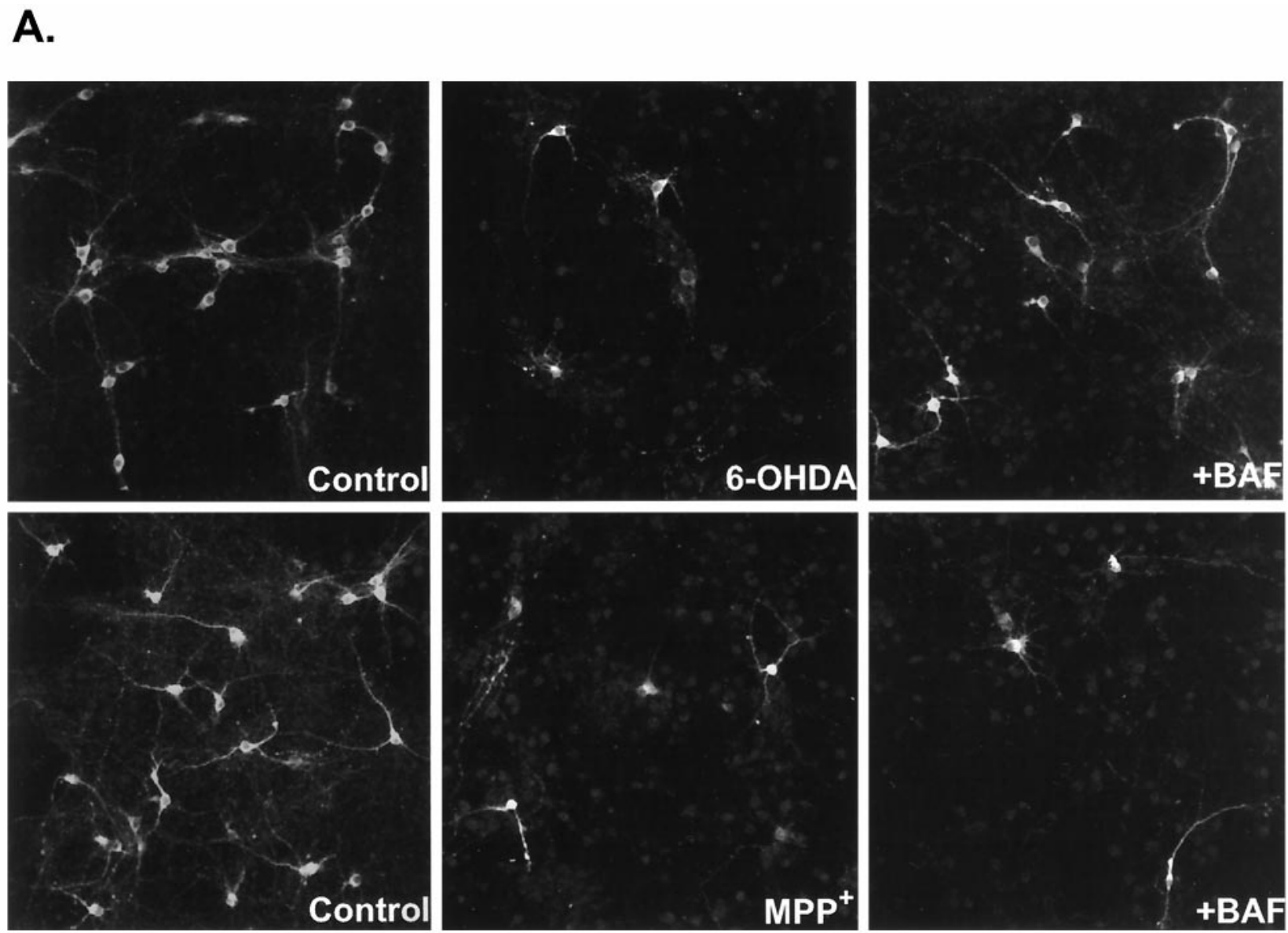

B.

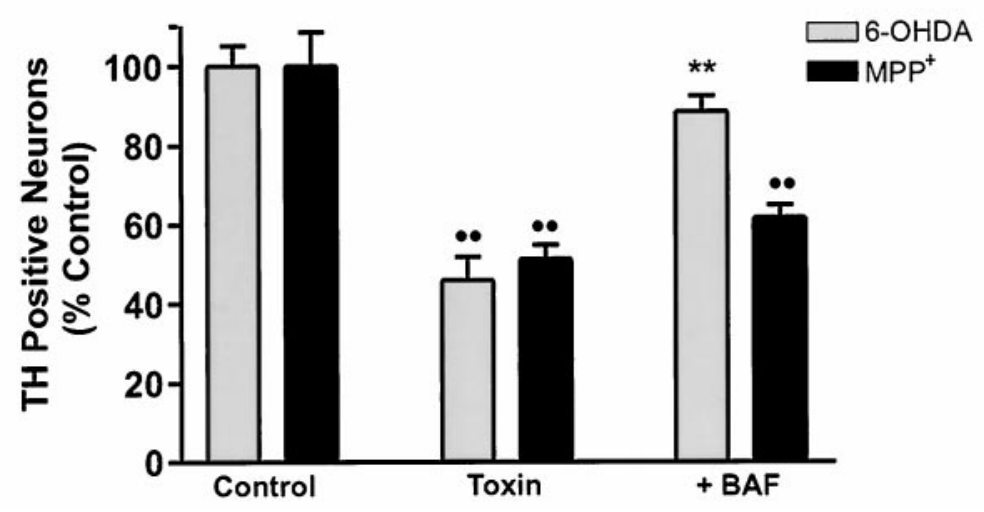

Figure 2. The caspase inhibitor BAF rescues cultured dopaminergic neurons from 6-OHDA but not $\mathrm{MPP}^{+}$ induced cell death. $A$, Representative fluorescent micrographs of mesencephalic cultures stained for TH and visualized using a CY3-conjugated secondary antibody. Cells were exposed to $15 \mu \mathrm{M}$ 6-OHDA or $1 \mu \mathrm{M} \mathrm{MPP}{ }^{+}$in the presence or absence of $50 \mu \mathrm{M} \mathrm{BAF}$ and stained after 24 and $48 \mathrm{hr}$, respectively. $B$, TH cell counts of cultures treated with either toxin and BAF. Values are normalized to the number of TH-positive neurons in vehicle-treated cultures and denote the mean \pm SEM made of three separate cultures. ${ }^{* *} p<0.001$ compared with toxintreated cultures; ${ }^{\bullet} p<0.001$ in relation to vehicle-treated control (ANOVA with post hoc Student's $t$ test).

calcium. Thus, potential neuroprotectants include glutamate receptor and/or calcium channel blockers, nitric oxide synthase (NOS) inhibitors, or the addition of various energy supplements. A range of concentrations of representative agents for each of these classes was tested. These included the noncompetitive NMDAR antagonist MK-801, the AMPA/kainate receptor antagonist NBQX, the Group I metabotropic glutamate receptor antagonist AIDA, the L-type calcium channel blocker nifedipine, the selective neuronal NOS inhibitor 7-NI, and the nonselective irreversible NOS inhibitor L-NNA. The maximal protection and the concentration at which it was achieved are listed in Table 1 . Both succinate and the two NOS inhibitors used, L-NNA and 7-NI, provided modest but significant protection. The various glutamate receptor and calcium channel blocks failed to attenuate $\mathrm{MPP}^{+}$-induced cell death (Table 1).

\section{DISCUSSION}

The combined use of apoptotic and free radical-sensitive fluorophores together with vital dyes and/or field relocation techniques have provided new insights into the cellular changes underlying 
5,7-DHT

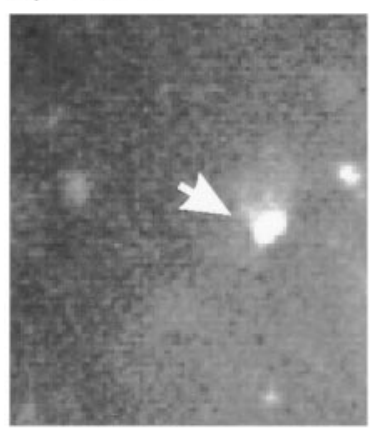

TH

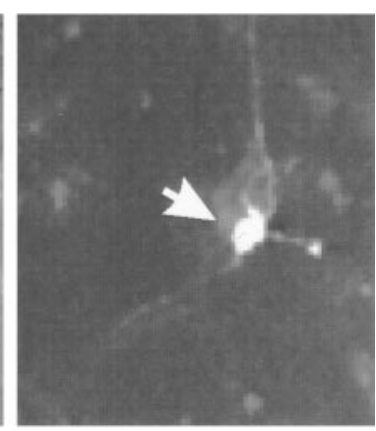

\section{DHE}

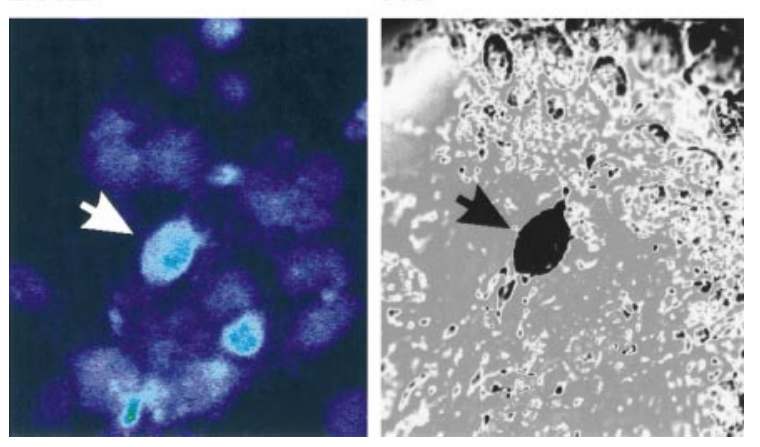

Figure 3. Identification of dopaminergic neurons using 5,7-DHT prelabeling or post hoc TH staining. Top panels, Mesencephalic cultures were incubated with $5,7-\mathrm{DHT}$ for $30 \mathrm{~min}$ at $37^{\circ} \mathrm{C}$, rinsed, and imaged by fluorescence microscopy with a computer-controlled camera. Images were taken at $40 \times$ magnification. Cultures were subsequently fixed and stained for TH using a CY3-coupled secondary antibody. Field relocation shows colocalization of TH with 5,7-DHT (white arrows). This methodology was used to assay changes in DHR and Rh 123 fluorescence in dopaminergic cells. Bottom panels, To measure DHE fluorescence in dopaminergic neurons, cultures were stained for TH via a color reaction after incubation with DHE. Bottom left panel, Confocal image of cells exposed to 6-OHDA for $30 \mathrm{~min}$ and incubated with DHE for $15 \mathrm{~min}(60 \times)$. On the right is the corresponding differential interference contrast image of TH-stained neurons in a relocated field.

toxin-mediated dopaminergic cell death. The present findings demonstrate that (1) 6-OHDA triggers apoptosis in cultured dopaminergic neurons, whereas $\mathrm{MPP}^{+}$does not; (2) the effects of 6-OHDA in vitro are not selective for dopaminergic neurons; (3) both toxins generate early bursts in ROS, although only 6-OHDA treatment depolarizes mitochondrial membrane potential $\left(\Delta \Psi_{\mathrm{m}}\right)$; and (5) the newly described buckminsterfullerene derivative $\mathrm{C}_{3}$ is more effective than GDNF in rescuing cells from 6-OHDA neurotoxicity, whereas, similar to GDNF, $\mathrm{C}_{3}$ suppresses a portion of the $\mathrm{MPP}^{+}$injury. Taken together these data demonstrate that 6-OHDA and $\mathrm{MPP}^{+}$kill cultured dopaminergic neurons by distinct cellular mechanisms.

Because these toxins have been widely used to create in vitro and in vivo animal models of $\mathrm{PD}$, it is somewhat surprising that the process or mechanism(s) by which 6-OHDA and $\mathrm{MPP}^{+}$kill cells has remained equivocal. Several parameters that may have confounded this issue include the delivery, severity, and duration of the toxin as well as the overlapping nature of some cell death processes activated during apoptosis or necrosis (PorteraCailliau et al., 1997). Moreover, apoptosis itself appears to be a "family" of cell death programs that proceed along similar but nonidentical pathways in response to disparate stimuli. The de- velopment of assays measuring changes in membrane lipid composition as well as caspase activation have improved our ability to confirm an apoptotic process. By these criteria, as well as by assays that detect DNA cleavage [terminal deoxynucleotidyl transferase-mediated biotinylated UTP nick end labeling (TUNEL), propidium iodide], 6-OHDA always resulted in apoptosis (data not shown). In contrast, even very low concentrations of $\mathrm{MPP}^{+}(\leq 1 \mu \mathrm{M})$ never induced externalization of phosphatidylserine in identified dopaminergic neurons (Fig. 1), nor could cell death be blocked by the general caspase inhibitor BAF (Fig. 2). Moreover, we found no evidence that TH-expressing neurons were TUNEL positive after $\mathrm{MPP}^{+}$treatments at doses as high as $10 \mu \mathrm{M}$ (data not shown). Finally, in many apoptotic paradigms, an early collapse in $\Delta \Psi_{\mathrm{m}}$ is observed that precedes nuclear apoptosis (for review, see Green and Reed, 1998). The marked 6-OHDAmediated collapse in $\Delta \Psi_{\mathrm{m}}$ and its absence in $\mathrm{MPP}^{+}$-treated dopaminergic neurons (Fig. $4 A$ ) further support the contention that 6-OHDA but not $\mathrm{MPP}^{+}$induces apoptosis in vitro.

Because both $\mathrm{MPP}^{+}$and 6-OHDA compete with dopamine for uptake via the plasma membrane transporter (Decker et al., 1993), their actions are generally thought to be selective for dopaminergic neurons. In our culture model, low concentrations of $\mathrm{MPP}^{+}$did appear to be specific, whereas even at very early time points after 6-OHDA treatment, 10-fold more neurons exhibited signs of apoptosis than could be accounted for by post hoc TH staining (Fig. 1B). Thus, at least in vitro, 6-OHDA appears to be a nonselective neurotoxin that induces apoptosis in dopaminergic and nondopaminergic neurons alike.

A number of previous studies both in vivo and in vitro have suggested that $\mathrm{MPP}^{+}$kills cells via apoptosis (Mochizuki et al., 1994; Itano and Nomura, 1995; Cassarino et al., 1998). Because most of these studies (1) have used at least 20-fold higher concentrations of drug, (2) have not confirmed the affected cell type or in some cases have not used dopaminergic cells, and/or (3) have relied solely on TUNEL positivity as an index of apoptosis, the interpretation that $\mathrm{MPP}^{+}$elicits apoptosis in bona fide dopaminergic neurons should be regarded with caution. Because TUNEL staining is also observed in many models of necrosis (Grasl-Kraupp et al., 1995; van Lookeren Campagne et al., 1995; Negoescu et al., 1996; Portera-Cailliau et al., 1997), additional criteria, including caspase blockade or activation, membrane perturbation, etc., are necessary to definitively establish that an apoptotic process is occurring. These studies highlight the need to first establish, in a simple system such as described here, the direct mechanism of cell loss attributable to $\mathrm{MPP}^{+}$toxicity to better interpret the more direct and complex processes in vivo.

$\mathrm{MPP}^{+}$toxicity in vivo is almost certainly influenced by striatal as well as cortical inputs. For example, $\mathrm{MPP}^{+}$has been shown to induce dopamine efflux and auto-oxidation resulting in hydroxyl radical formation (Obata and Chiueh, 1992). Glutamatergic inputs may be a target for these free radicals, leading to glutamate release, impaired reuptake, and further damage to dopaminergic neurons by excitotoxicity. Additionally, the complex metabolism of MPTP itself, the mode of administration, and/or the presence of other factors that might be missing in cultured neurons can all potentially alter a cell's susceptibility to death, further complicating in vivo versus in vitro results.

Green and Reed (1998) have proposed a model by which mitochondria mediate both apoptotic and nonapoptotic cell death via several related mechanisms, including impairment of electron transport and $\Delta \Psi_{\mathrm{m}}$, release of proteins that activate caspase family members, and alterations in cellular redox potential. Thus, 
A. Rhodamine 123

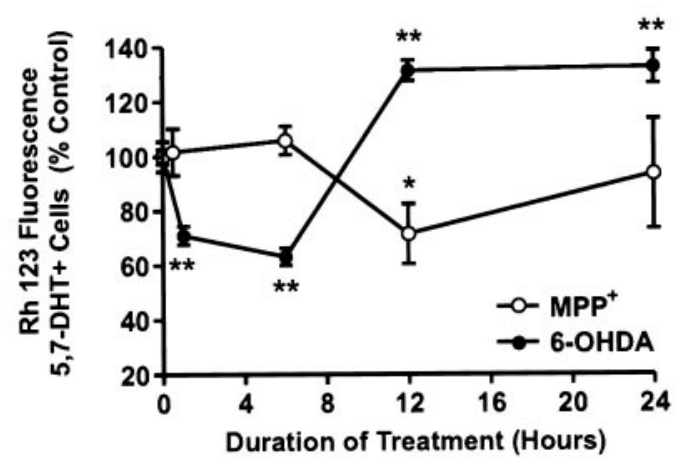

\section{B. Dihydrorhodamine}

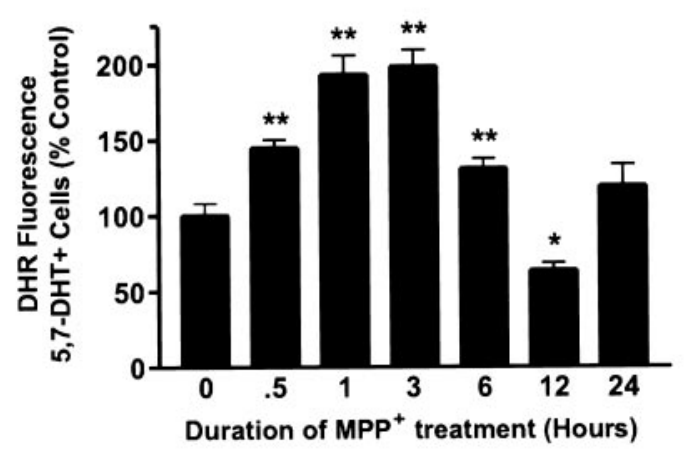

\section{Dihydroethidium}

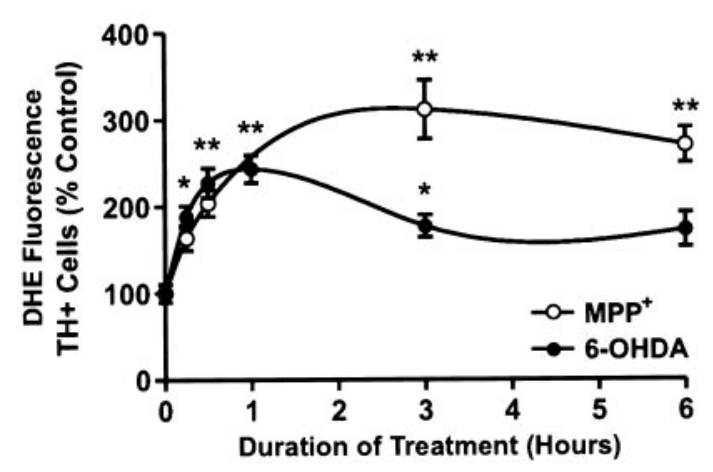

Figure 4. 6-OHDA and $\mathrm{MPP}^{+}$differentially affect mitochondrial membrane potential $\left(\Psi \Delta_{\mathrm{m}}\right)$ and induce ROS formation. $A$, Time course of $\Psi \Delta_{\mathrm{m}}$ in 5,7-DHT-labeled dopaminergic neurons treated with $15 \mu \mathrm{M}$ 6-OHDA (๑) or $1 \mu \mathrm{M} \mathrm{MPP}{ }^{+}(\bigcirc)$. After drug treatments, cells were loaded with 0.3 $\mu \mathrm{M}$ Rh 123 for 20 min and assayed using a laser scanning confocal microscope. Values correspond to average pixel intensity normalized to baseline fluorescence values from vehicle-treated cells. $B$, Time-dependent changes in ROS production in dopaminergic neurons treated with $1 \mu \mathrm{M} \mathrm{MPP}{ }^{+}$. After treatment with $1 \mu \mathrm{M} \mathrm{MPP}{ }^{+}$for the indicated time period, cells were incubated with $15 \mu \mathrm{M}$ DHR for $20 \mathrm{~min}$, rinsed, and imaged by confocal microscopy. Values correspond to fluorescence intensity and are normalized to vehicle-treated labeled dopaminergic neurons. $C$, Time-dependent induction of ROS formation in dopaminergic neurons treated with $15 \mu \mathrm{M}$ 6-OHDA or $1 \mu \mathrm{M} \mathrm{MPP}{ }^{+}$. After treatment with either drug for $0,0.25,0.5$, 1,3 , and $6 \mathrm{hr}$, cells were loaded with $10 \mu \mathrm{g} / \mathrm{ml} \mathrm{DHE}$ for $15 \mathrm{~min}$ at $37^{\circ} \mathrm{C}$, fixed, stained for $\mathrm{TH}$, and assayed by confocal microscopy. Values represent normalized DHE fluorescence from TH-immunoreactive neurons. Data are mean \pm SEM of determinations made in three separate cultures. ${ }^{*} p<$ $0.01 ; * * p<0.001$, compared with values for vehicle-treated cultures (ANOVA with post hoc Student's $t$ test). mitochondria represent both a target for cell death processes and a source of cytotoxic oxygen radicals. Previous studies would suggest that $\mathrm{MPP}^{+}$affects the first of these processes by blocking Complex I activity, which leads to decreased ATP levels, alterations in membrane permeability, and calcium influx akin to excitotoxic cell death processes (for review, see Jenner, 1998). Such a model would predict an early loss in $\Delta \Psi_{\mathrm{m}}$, superoxide formation, and a subsequent cellular energy drain (White and Reynolds, 1996). In contrast to these predictions, we saw no early perturbations of mitochondrial membrane potential (Fig. 4A), nor could we block $\mathrm{MPP}^{+}$-mediated cell death with ionotropic/ metabotropic glutamate or calcium channel antagonists (Table 1). Similarly, glycolytic and Complex II substrates, which would be expected to suppress $\mathrm{MPP}^{+}$neurotoxicity by providing an alternative source of ATP, were largely ineffective (Table 1). Thus, the specific $\mathrm{MPP}^{+}$-induced signals that lead to cell death are not solely mediated by a loss of mitochondrial ATP production. In agreement with this hypothesis, Khan et al. (1997) showed recently that $\mathrm{MPP}^{+}$was as toxic to cells without mitochondria as it was to cells with normal mitochondrial function. Further studies of temporal events associated with $\mathrm{MPP}^{+}$toxicity will help to clarify this intriguing issue.

Oxidation of DHR has been used as a measure of mitochondrial ROS formation (Dugan et al., 1995). As such, it is thought to measure radicals such as hydroxyl and peroxynitrite both directly and indirectly via the conversion of superoxide (Henderson and Chappell, 1993). The successful utilization of DHR depends on maintenance of $\Delta \Psi_{\mathrm{m}}$, a decline in which precluded its use for 6-OHDA experiments. Because $\mathrm{MPP}^{+}$treatment did not alter $\Delta \Psi_{\mathrm{m}}$ (Fig. $3 A$ ), we were able to observe a burst in DHR fluorescence in identified dopaminergic neurons as early as 30 min after $\mathrm{MPP}^{+}$treatment before a peak at $3 \mathrm{hr}$ (Fig. 4B). This time course paralleled that of DHE (Fig. 4C), which preferentially reacts with superoxide. In contrast to in vivo studies (Smith et al., 1994; Przedborski et al., 1996), the NOS inhibitors 7-N I and L-NNA protected only a small percentage $(16 \%)$ of neurons from $\mathrm{MPP}^{+}$treatment (Table 1). These data would suggest that, at least in vitro, peroxynitrite is only a small component of the $\mathrm{MPP}^{+}$injury. Rather, superoxide appears to be the primary radical involved. This is consistent with data from Ramsay and Singer (1992) showing that partial ubiquinone oxidation resulting from $\mathrm{MPP}^{+}$blockade of Complex I can lead to superoxide formation in submitochondrial particles.

We observed a late $(12 \mathrm{hr})$ decline in $\Delta \Psi_{\mathrm{m}}$ after $\mathrm{MPP}^{+}$ treatment, consistent with its action as an inhibitor of Complex I. The subsequent return to near normal values at $24 \mathrm{hr}$ could be explained by the selection of a subpopulation of $\mathrm{MPP}^{+}$-resistant neurons using 5,7-DHT labeling. Although the classic Complex I inhibitor rotenone generally results in a tight block of electron transport flow and subsequent membrane depolarization (Simbula et al., 1997), MPP ${ }^{+}$produces only a partial block of Complex I activity (Gluck et al., 1994), which might allow the membrane potential to be maintained for some time. Moreover, "reversed" function of the $\mathrm{F}_{1} / \mathrm{F}_{0} \mathrm{ATPase}$, using ATP hydrolysis to pump protons together with ATP generated through glycolysis, could temporarily support $\Delta \Psi_{\mathrm{m}}$ (Mitchell and Moyle, 1968). $\mathrm{MPP}^{+}$-induced ROS generation likely reflects inhibition of Complex I, which might further the energy impairment produced by $\mathrm{MPP}^{+}$itself. Thus, oxidative inactivation of key components of both the electron transport chain and the glycolytic pathway might contribute to a subsequent "metabolic death." This might 

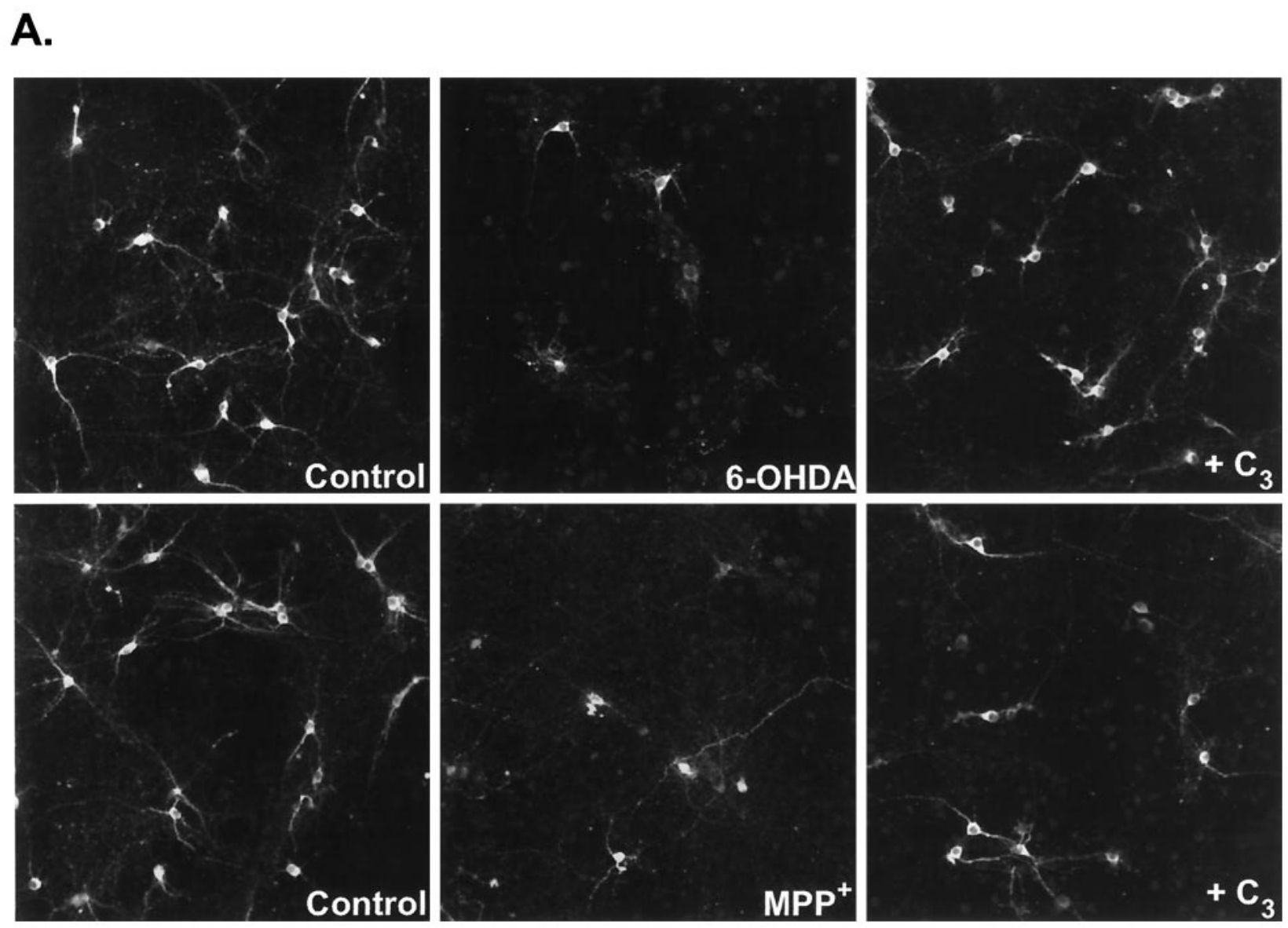

B.

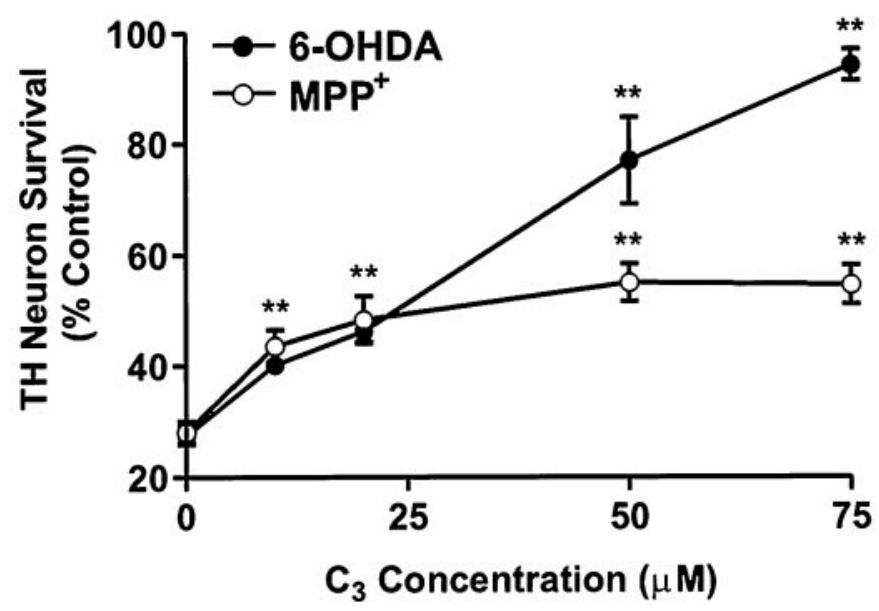

Figure 5. The $\mathrm{C}_{3}$ fullerene isomer protects cultured dopaminergic neurons from 6-OHDA-induced toxicity but only partially attenuates $\mathrm{MPP}^{+}$-mediated cell death. $A$, Representative fluorescent micrographs of TH-positive neurons treated with either $15 \mu \mathrm{M}$ 6-OHDA or $1 \mu \mathrm{M} \mathrm{MPP}{ }^{+}$in the presence or absence of $75 \mu \mathrm{M} \mathrm{C}_{3}$. $B$, Dose-dependent effects of $\mathrm{C}_{3}$ on dopaminergic neurons treated with $15 \mu \mathrm{M}$ 6-OHDA $(\bullet)$ or $1 \mu \mathrm{M} \mathrm{MPP}^{+}(\bigcirc)$. The number of surviving dopaminergic neurons was determined $24 \mathrm{hr}$ (6-OHDA) or $48 \mathrm{hr}\left(\mathrm{MPP}^{+}\right)$later by $\mathrm{TH}$ immunocytochemistry and normalized to the number of TH neurons in vehicle-treated plates. Data are mean \pm SEM from determinations made from three cultures. ${ }^{*} p<0.01 ; * *<0.001$ compared with values from control plates (ANOVA with post hoc Student's $t$ test).

explain why antioxidants provide only partial protection against $\mathrm{MPP}^{+}$injury.

In contrast, neurons exposed to 6-OHDA showed rapid loss of mitochondrial membrane potential, followed by rebound hyperpolarization. We believe this reflects early oxidative inactivation of components from mitochondrial and glycolytic metabolic pathways by 6-OHDA. Glyceraldehyde-3-phosphate dehydrogenase (GAPDH), for example, can undergo reversible oxidative inactivation by $\mathrm{H}_{2} \mathrm{O}_{2}$ (Janero et al., 1994). This inhibition might limit the ability of glycolysis to support $\Delta \Psi_{\mathrm{m}}$ in the face of Complex 


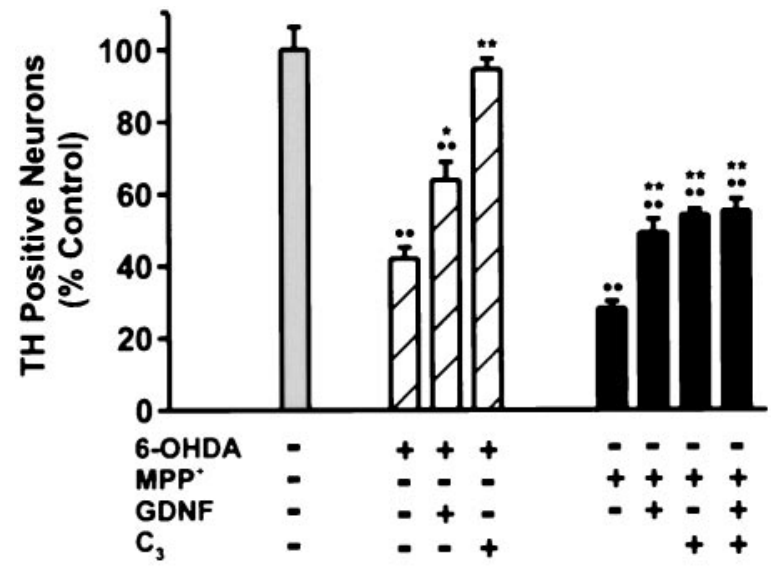

Figure 6. Effects of $\mathrm{C}_{3}$ and/or GDNF in rescuing dopaminergic neurons from neurotoxin-induced cell death. Primary mesencephalic cultures were pretreated with $1 \mathrm{ng} / \mathrm{ml}$ rhGDNF for $3 \mathrm{hr}$ before the addition of either 15 $\mu \mathrm{M}$ 6-OHDA (hatched bars) or $1 \mu \mathrm{M} \mathrm{MPP}{ }^{+}$(black bars). The fullerene isomer $\mathrm{C}_{3}(75 \mu \mathrm{M})$ was tested for its ability to enhance the protective effect of GDNF. Dopaminergic cell viability was assessed $24 \mathrm{hr}$ (6OHDA) and $48 \mathrm{hr}\left(\mathrm{MPP}^{+}\right)$later by $\mathrm{TH}$ immunocytochemistry. Data denote the mean \pm SEM. Asterisks indicate statistically significant difference between each respective drug condition and GDNF or GDNF with $\mathrm{C}_{3} .{ }^{*} p<0.01 ;{ }^{* *} p<0.001 ;{ }^{*} p<0.001$ shows difference between vehicle-treated control and all conditions (ANOVA with post hoc Student's $t$ test).

\begin{tabular}{|c|c|}
\hline Drug class & Survival ( $\%$ of control) \\
\hline $1 \mu \mathrm{M} \mathrm{MPP}+$ & $25.40 \pm 4.49$ \\
\hline \multicolumn{2}{|c|}{ Glutamate/calcium channel inhibitors } \\
\hline $1 \mu \mathrm{M} \mathrm{MK}-801$ & $25.40 \pm 8.98$ \\
\hline $30 \mu \mathrm{M}$ NBQX & $25.40 \pm 5.99$ \\
\hline $300 \mu \mathrm{M}$ AIDA & $29.63 \pm 5.18$ \\
\hline $10 \mu \mathrm{M}$ nifedipine & $38.10 \pm 10.37$ \\
\hline \multicolumn{2}{|l|}{ Metabolic substrates } \\
\hline $10 \mathrm{~mm}$ glucose & $33.31 \pm 7.87$ \\
\hline $0.5 \mathrm{~mm}$ succinate & $36.80 \pm 1.47^{* *}$ \\
\hline \multicolumn{2}{|l|}{ NOS inhibitors } \\
\hline $1 \mu \mathrm{M} \mathrm{MPP}{ }^{+}$ & $28.00 \pm 2.92$ \\
\hline $2.5 \mathrm{~mm}$ nitro-L-arginine & $40.00 \pm 3.34^{*}$ \\
\hline $5 \mu \mathrm{M}$ 7-nitroindazole & $40.00 \pm 2.3$ \\
\hline
\end{tabular}

Primary mesencephalic cultures were treated with $1 \mu \mathrm{M} \mathrm{MPP}{ }^{+}$in the presence of the indicated drugs and stained for $\mathrm{TH} 48 \mathrm{hr}$ later. The number of surviving $\mathrm{TH}$ neurons was normalized to vehicle-treated controls. Data are mean \pm SEM. ${ }^{*} p<$ $0.01,{ }^{*} * p<0.001$ compared with $\mathrm{MPP}^{+}$-treated cultures (ANOVA with post hoc Student's $t$ test).

I/IV inhibition by 6-OHDA (Glinka and Youdim, 1995). Presumably, once 6-OHDA is completely oxidized, inhibition of GAPDH is reversed, allowing glycolysis to resume. Mitochondrial hyperpolarization observed at later time points has also been described in other systems during apoptosis (for review, see Green and Reed, 1998).

Recently, spherical, water-soluble derivatives of $\mathrm{C}_{60}$ molecules (carboxyfullerenes), have been shown to act as unique antioxidants in several models of oxidative stress, including excitotoxic necrosis and apoptosis induced by $\mathrm{A} \beta_{1-42}$ peptide or serum deprivation, as well as in an animal model of familial amyotrophic lateral sclerosis (Dugan et al., 1997). Dubbed "radical sponges"
(Krusic et al., 1991), their efficacy stems from their extensive system of interconnected double bonds that are highly reactive with ROS (Krusic et al., 1991), particularly hydroxyl and superoxide radicals (Dugan et al., 1997). The significant levels of protection observed after treatment with the amphiphilic fullerene isomer $\mathrm{C}_{3}$ (Fig. $5 A, B$ ) extends the usefulness of these compounds to in vitro models of $\mathrm{PD}$. Intriguingly, the $\mathrm{C}_{3}$ fullerene was more effective than a known dopaminergic neuroprotectant, GDNF (Lin et al., 1993), in rescuing dopaminergic viability. Although the exact mechanisms by which trophic factors exert their effects are unknown, studies have suggested that attenuation of oxidative damage may be an important component. For example, transforming growth factor- $\beta$, the prototype of a superfamily of growth factors that includes GDNF, protects neurons from ROS by, among other things, inhibiting NOS activity and by maintenance of $\Delta \Psi_{\mathrm{m}}$ (for review, see Flanders et al., 1998). Our data also imply that GDNF can protect dopamine cells from at least one component of oxidative stress. In contrast, $\mathrm{C}_{3}$ fullerenes appear to rescue a broader spectrum of ROS sources.

In summary, although the neurotoxins $\mathrm{MPP}^{+}$and 6-OHDA elicit unique forms of cell death, $\mathrm{MPP}^{+}$and 6-OHDA both induce early bursts in ROS production. Because impaired ROS homeostasis has been implicated in PD, the development of antioxidants is a promising therapeutic goal. Given the various mechanisms of cell death associated with PD, including oxidative stress, excitotoxicity, trophic factor deficiency, etc., as well as the lack of consensus regarding cell death type (apoptosis vs necrosis), carboxyfullerene derivatives represent a potential broadspectrum protectant that might prove to be most useful in this disorder.

\section{REFERENCES}

Bindokas VP, Jordan J, Lee CC, Miller RJ (1996) Superoxide production in rat hippocampal neurons: selective imaging with hydroethidine. J Neurosci 16:1324-1336.

Cardozo DL (1993) Midbrain dopaminergic neurons from postnatal rat in long-term primary culture. Neuroscience 56:409-421.

Cardozo DL, Bean BP (1995) Voltage-dependent calcium channels in rat midbrain dopamine neurons: modulation by dopamine and $\mathrm{GABA}_{\mathrm{B}}$ receptors. J Neurophysiol 74:1137-1148.

Cassarino DS, Fall CP, Smith TS, Bennett Jr JP (1998) Pramipexole reduces reactive oxygen species production in vivo and in vitro and inhibits the mitochondrial permeability transition produced by the parkinsonian neurotoxin methylpyridinium ion. J Neurochem 71:295-301.

Cohen G, Heikkila RE (1974) The generation of hydrogen peroxide, superoxide radical, and hydroxyl radical by 6-hydroxydopamine, dialuric acid, and related cytotoxic agents. J Biol Chem 249:2447-2452.

Decker DE, Althaus JS, Buxser SE, VonVoigtlander PF, Ruppel PL (1993) Competitive irreversible inhibition of dopamine uptake by 6-hydroxydopamine. Res Commun Chem Pathol Pharmacol 79:195-208.

de Erausquin G, Brooker G, Costa E, Hanbauer I (1994) Persistent AMPA receptor stimulation alters $\left[\mathrm{Ca}^{2+}\right]_{\mathrm{i}}$ homeostasis in cultures of embryonic dopaminergic neurons. Brain Res Mol Brain Res 21:303-311.

Dugan LL, Sensi SL, Canzoniero LMT, Handran SD, Rothman SM, Lin TS, Goldberg MP, Choi DW (1995) Mitochondrial production of reactive oxygen species in cortical neurons following exposure to $N$-methyl-D-aspartate. J Neurosci 15:6377-6388.

Dugan LL, Turetsky DM, Du C, Lobner D, Wheeler M, Almli CR, Shen CK, Luh TY, Choi DW, Lin TS (1997) Carboxyfullerenes as neuroprotective agents. Proc Natl Acad Sci USA 94:9434-9439.

Flanders KC, Ren RF, Lippa CF (1998) Transforming growth factorbetas in neurodegenerative disease. Prog Neurobiol 54:71-85.

Gerlach M, Gotz, M, Dirr A, Kupsch A, Janetzky B, Oertel W, Sautter, J, Schwarz, J, Reichmann H, Riederer P (1996) Acute MPTP treatment produces no changes in mitochondrial complex activities and indices of oxidative damage in the common marmoset ex vivo one week after exposure to the toxin. Neurochem Int 28:41-49. 
Glinka Y, Youdim MBH (1995) Inhibition of mitochondrial complexes I and IV by 6-hydroxydopamine. Eur J Pharmacol 292:329-332.

Gluck MR, Krueger MJ, Ramsay RR, Sablin SO, Singer TP, Nicklas WJ (1994) Characterization of the inhibitory mechanism of 1-methyl-4phenylpyridinium and 4-phenylpyridine analogs in inner mitochondrial membrane preparations. J Biol Chem 269:3167-3174.

Grasl-Kraupp B, Ruttkay-Nedecky B, Koudelka H, Bukowska K, Bursch W, Schulte-Hermann R (1995) In situ detection of fragmented DNA (TUNEL assay) fails to discriminate among apoptosis, necrosis, and autolytic cell death: a cautionary note. Hepatology 21:1465-1468.

Green DR, Reed JC (1998) Mitochondria and apoptosis. Science 281:1309-1312.

Graham DG, Tiffany SM, Bell WR, Gutknecht WF (1978) Autooxidation versus covalent binding of quinones as the mechanism of toxicity of dopamine, 6-hydroxydopamine, related compounds toward C1300 neuroblastoma cells in vitro. Mol Phamacol 14:644-653.

Hantraye P, Brouillet E, Ferrante R, Palfi S, Dolan R, Matthews RT, Beal MF (1996) Inhibition of neuronal nitric oxide synthase prevents MPTP-induced parkinsonism in baboons. Nat Med 2:1017-1021.

Henderson LM, Chappell JB (1993) Dihydrorhodamine 123: a fluorescent probe for superoxide generation? Eur J Biochem 217:973-980.

Itano Y, Nomura Y (1995) 1-methyl-4-phenyl-pyridinium ion $\left(\mathrm{MPP}^{+}\right)$ causes DNA fragmentation and increases the Bcl-2 expression in human neuroblastoma, SH-SY5Y cells, through different mechanisms. Brain Res 704:240-245.

Janero DR, Hreniuk D, Sharif HM (1994) Hydroperoxide-induced oxidative stress impairs heart muscle cell carbohydrate metabolism. Am J Physiol 266:C179-C188.

Jenner P (1998) Oxidative mechanisms in nigral cell death in Parkinson's disease. Mov Disord 13:24-34.

Khan U, Filiano B, King M, Przedborski S (1997) Is Parkinson's disease (PD) an extra-mitochondrial disorder? Neurology 48:A201.

Krusic PJ, Wasserman E, Keizer PN, Morton JR, Preston KF (1991) Radical reactions of $\mathrm{C}_{60}$. Science 254:1183-1185.

Lapchak PA (1998) A preclinical development strategy designed to optimize the use of glial cell line-derived neurotrophic factor in the treatment of Parkinson's disease. Mov Disord 13:49-54.

Lin LF, Doherty DH, Lile JD, Bektesh S, Collins F (1993) GDNF: a glial cell line-derived neurotrophic factor for midbrain dopaminergic neurons. Science 260:1130-1132.

Mitchell P, Moyle J (1968) Proton translocation coupled to ATP hydrolysis in rat liver mitochondria. Eur J Biochem 4:530-539.

Mochizuki H, Nakamura N, Nishi K, Mizuno Y (1994) Apoptosis is induced by 1 -methyl-4-phenylpyridinium ion $\left(\mathrm{MPP}^{+}\right)$in ventral mesencephalic-striatal co-culture in rat. Neurosci Lett 170:191-194.

Negoescu A, Lorimier P, Labat-Moleur F, Drouet C, Robert C, Guillermet C, Brambilla C, Brambilla E (1996) In situ apoptotic cell labeling by the TUNEL method: improvement and evaluation on cell preparations. J Histochem Cytochem 4:959-968.
Obata T, Chiueh CC (1992) In vivo trapping of hydroxyl free radicals in the striatum utilizing intracranial microdialysis perfusion of salicylate: effects of MPTP, MPDP ${ }^{+}$, and MPP ${ }^{+}$. J Neural Transm 89:139-145.

Portera-Cailliau C, Price DL, Martin LJ (1997) Non-NMDA and NMDA receptor-mediated excitotoxic neuronal deaths in adult brain are morphologically distinct: further evidence for an apoptosis-necrosis continuum. J Comp Neurol 3781:88-104.

Przedborski S, Jackson-Lewis V (1998) Mechanisms of MPTP toxicity. Mov Disord 13:35-38.

Przedborski S, Kostic V, Jackson-Lewis V, Naini AB, Simonetti S, Fahn S, Carlson E, Epstein CJ, Cadet JL (1992) Transgenic mice with increased $\mathrm{Cu} / \mathrm{Zn}$-superoxide dismutase activity are resistant to $N$-methyl-4-phenyl-1,2,3,6-tetrahydropyridine-induced neurotoxicity. J Neurosci 12:1658-1667.

Przedborski S, Jackson-Lewis V, Yokoyama R, Shibata T, Dawson VL, Dawson TM (1996) Role of neuronal nitric oxide in 1-methyl-4phenyl-1,2,3,6-tetrahydropyridine (MPTP)-induced dopaminergic neurotoxicity. Proc Natl Acad Sci USA 93:4565-4571.

Ramsay RR, Singer TP (1992) Relation of superoxide generation and lipid peroxidation to the inhibition of NADH-Q oxidoreductase by rotenone, piercidin $\mathrm{A}$, and $\mathrm{MPP}^{+}$. Biochem Biophys Res Commun 189:47-52.

Royall JA, Ischoropoulos H (1993) Evaluation of 2',7'-dichlorofluorescein and dihydrorhodamine 123 as fluorescent probes for intracellular $\mathrm{H}_{2} \mathrm{O}_{2}$ in cultured endothelial cells. Arch Biochem Biophys 302:348-355.

Silva NL, Mariani AP, Harrison NL, Barker JL (1988) 5,7dihydroxytryptamine identifies living dopaminergic neurons in mesencephalic cultures. Proc Natl Acad Sci USA 85:7346-7350.

Simbula G, Glascott Jr PA, Akita S, Hoek JB, Farber JL (1997) Two mechanisms by which ATP depletion potentiates induction of the mitochondrial permeability transition. Am J Physiol 273:C479-C488.

Smith, TS, Swerdlow, RH, Parker WD, Bennett JP (1994) Reduction of $\mathrm{MPP}^{+}$-induced hydroxyl radical formation and nigrostriatal MPTP toxicity by inhibiting nitric oxide synthase. NeuroReport 5:2598-2600.

Thornberry NA, Lazebnik Y (1998) Caspases: enemies within. Science 281:1312-1316.

van Engeland M, Nieland LJ, Ramaekers FC, Schutte B, Reutelingsperger CP (1998) Annexin V-affinity assay: a review on an apoptosis detection system based on phosphatidylserine exposure. Cytometry 31:1-9.

van Lookeren Campagne M, Lucassen PJ, Vermeulen JP, Balazs R (1995) NMDA and kainate induce internucleosomal DNA cleavage associated with both apoptotic and necrotic cell death in the neonatal rat brain. Eur J Neurosci 7:1627-1640.

White RJ, Reynolds IJ (1996) Mitochondrial depolarization in glutamate-stimulated neurons: an early signal specific to excitotoxin exposure. J Neurosci 16:5688-5697. 